\title{
Model Pemberdayaan Ekonomi Perempuan di Kabupaten Nias Berbasis Sumber Daya Lokal
}

\author{
Nenny Anggraini \\ Universitas Kristen Indonesia \\ Desideria Regina \\ Universitas Kristen Indonesia
}

\begin{abstract}
Abstrak: Perempuan mempunyai peran yang strategis dalam pembangunan di Indonesia, termasuk perempuan di wilayah pedesaan di daerah teringgal. Strategi pembangunan perempuan di daerah teringgal dilakukan dengan meningkatkan partisipasi, supaya kesejahteraan segera terwujud. Untuk itu , perlu diberikan pelatihan pengolahan bahan-bahan lokal kepada perempuan. Perempuan saat ini dituntut aktif dalam pemanfaatan sumber daya lokal. Wilayah Kabupaten Nias, sistem budaya patriarkhi masih sangat kuat; perempuan cenderung ditempatkan di sektor domestik, sehingga seringkali tidak bernilai ekonomi tinggi. Oleh karena itu diperlukan model pemberdayaan perempuan dengan melibatkan perempuan secara aktif. Model ini adalah dengan memanfaatkan sumber daya lokal. Dengan demikian diharapkan kehidupan ekonomi dan kesejahteraan keluarga meningkat.
\end{abstract}

Kata Kunci: Model Pemberdayaan Perempuan, Pemanfaatan Sumber Daya Lokal

Abstract: Women have strategic roles in general development in Indonesia, including women who live in underdeveloped region. Women development strategy in underdeveloped regions performed with enhancing their participations, in order to make the welfare come true. Therefore, they need the local materials processing training. Women nowadays are demanded to be active to utilize local resources. In district of Nias, the patriarchy cultural system is still very strong; women are tended to be placed in domestic sector so that it does not have high economy values. Hence they need the women empowerment model by involving women actively in utilizing local resources. Therefore, it is expected that their economy and family welfare could be increased.

Key Words: Women empowerment model, local resources utilization

Koresponden penulis:

Nenny Anggraini, Desideria Regina

Fakultas Ekonomi dan Bisnis Universitas Kristen Indonesia

Jl. Mayjen Sutoyo No. 2, Cawang, Jakarta Timur.

E-mail: nennysus@yahoo.com,reginadesi@yahoo.com 


\section{PENDAHULUAN}

Peran perempuan dalam pembangunan masih terbatas. Disadari bahwa kualitas sumber daya perempuan saat ini pada umumnya masih tertinggal dibandingkan dengan lakilaki. Hal ini menjadi salah satu dampak dari sistem pembangunan yang masih belum sepenuhnya memberikan ruang dan kesempatan yang sama kepada perempuan dan laki-laki. Dalam menghadapi berbagai persoalan itu, perlu dibangkitkan kesadaran terhadap peran strategis perempuan Indonesia. Kesadaran kolektif kaum perempuan harus dibangkitkan agar tidak mendapatkan perlakuan diskriminatif. Oleh karena itu, strategi pembangunan daerah pedesaan yang merupakan wilayah daerah teringgal, dilakukan dengan meningkatkan partisipasi perempuan dalam program pengentasan kemiskinan. Hal ini perlu mendapat perhatian agar kesejahteraan masyarakat segera terwujud.

Upaya pemberdayaan perempuan di Indonesia terutama di pedesaan telah dilakukan melalui berbagai cara. Program pemberdayaan yang dilakukan selama ini hanya memperhatikan peran perempuan sebagai obyek alih-laih sebagai subjek. Sehingga, kurang memberikan hasil signifikan. Oleh karena itu perlu strategi yang melibatkan perempuan secara aktif. Keberhasilan program pemberdayaan perempuan ditentukan oleh keterlibatan beberapa pihak. Pemerintah dan masyarakat perlu mengikutsertakan perempuan itu sendiri secara komprehensif. Salah satu alternatif yang dapat dilakukan adalah memberdayakan perempuan melalui pemanfaatan sumber daya lokal. Diyakini bahwa akses sumber daya lokal menjadi variabel penting yang berpengaruh terhadap pembangunan ekonomi di daerah tertinggal. Dengan demikian diharapkan kehidupan ekonomi dan kesejahteraan keluarga meningkat. 
Strategi pembangunan perempuan di daerah teringgal dilakukan dengan meningkatkan partisipasi, untuk dapat mewujudkan kesejahteraan masyarakat. Untuk itu, perlu diberikan pelatihan pengolahan bahan-bahan lokal kepada perempuan. Saat ini, perempuan dituntut aktif dalam pemanfaatan sumber daya lokal.

Di Kabupaten Nias, sistem budaya patriarki masih sangat kuat; perempuan cenderung ditempatkan di sektor domestik, sehingga seringkali tidak bernilai ekonomi tinggi (Anggraini, Mita, Lase, 2016, 2). Oleh karena itu diperlukan model pemberdayaan perempuan yang melibatkan perempuan secara aktif dengan memanfaatkan sumber daya lokal.

Kabupaten Nias merupakan salah satu kabupaten di Propinsi Sumatera Utara yang berada dalam satu pulau yang disebut pulau Nias. Pulau Nias mempunyai jarak \pm 85 mil laut dari Sibolga yang berada di dataran Sumatera Utara. Kabupaten Nias yang termasuk wilayah daerah tertinggal terdiri dari 10 kecamatan yaitu : Bawölato, Botomuzöi, Gidö, Hili Serangkai, Hiliduho, Idanögawo, Ma'u, Somölö-mölö, Ulugawo, dan Sogae'adu. Luas wilayah Kabupaten Nias adalah $1.004,06 \mathrm{~km}^{2}$; sejajar dan berada di sebelah barat Pulau Sumatera serta dikelilingi oleh Samudera Hindia. Menurut letak geografis, Kabupaten Nias terletak pada garis $0012^{\circ}-1032^{0}$ Lintang Utara (LU) dan $970^{\circ}$ - 980 Bujur Timur (BT) dekat dengan garis khatulistiwa, dengan batas - batas wilayah : Sebelah Utara : berbatasan dengan Kabupaten Nias Utara; Sebelah Selatan : berbatasan dengan Kabupaten Nias Selatan; Sebelah Timur : berbatasan dengan Kota Gunungsitoli dan Samudera Indonesia dan sebelah Barat : berbatasan dengan Kabupaten Nias Barat.

Aksesibilitas ke wilayah ini tergolong sulit, karena hanya dapat dilalui dengan transportasi udara dan laut dengan frekuensi yang terbatas. Hal ini sangat memengaruhi perkembangan kabupaten Nias, dimana ketergantungan Kabupaten Nias 
dengan wilayah luar sangat besar. Jumlah penduduk Kabupaten Nias pada tahun 2015 sebanyak 140.613 orang, terdiri dari 72.165 penduduk perempuan dan 68.448 penduduk laki-laki. Secara terinci dapat di lihat pada Tabel 1 di bawah ini :

Tabel 1. Jumlah Penduduk Berdasarkan Jenis Kelamin

\begin{tabular}{|l|c|c|c|c|}
\hline \multirow{3}{*}{ Kecamatan District } & \multicolumn{3}{|c|}{ Jumlah Penduduk } & \multirow{2}{*}{$\begin{array}{c}\text { Rasio Jenis } \\
\text { (Sex Ratio) }\end{array}$} \\
\cline { 2 - 5 } & Laki-laki & $\begin{array}{c}\text { Perempuan } \\
\text { Male }\end{array}$ & $\begin{array}{c}\text { Jumlah } \\
\text { Total }\end{array}$ & \\
\hline Id) & $(2)$ & $(3)$ & $(4)$ & $(5)$ \\
\hline Bawöölato & 13,257 & 13,569 & 26,826 & 97,70 \\
\hline Ulugawo & 11,683 & 12,277 & 23,960 & 95,16 \\
\hline Gidö & 4,949 & 5,142 & 10,091 & 96,25 \\
\hline Sogaeadu & 10,516 & 10,719 & 21,235 & 98,11 \\
\hline Ma'u & 4,465 & 5,218 & 9,683 & 85,57 \\
\hline Somölö-mölö & 3,068 & 3,352 & 6,420 & 91,53 \\
\hline Hiliduho & 4,586 & 4,835 & 9,421 & 94,85 \\
\hline Hili Serangkai & 5,904 & 6,610 & 12,514 & 89,32 \\
\hline Botomuzöi & 4,492 & 4,906 & 9,398 & 91,56 \\
\hline NIAS & 5,528 & 5,537 & 11,065 & 99,84 \\
\hline
\end{tabular}

Sumber/source : BPS Kabupaten Nias/BPS - Statistics of Nias Regency 2015

Secara sosiokultural, masyarakat Nias adalah kelompok suku dengan budaya patriarki yang khas. Laki-laki dan perempuan mempunyai peran dan kedudukan yang berbeda di masyarakat di mana laki-laki berperan sangat penting dan menjadi yang utama. Dalam sebuah pesta adat, perempuan terbatas bergerak di dalam rumah, memasak dan mencuci seluruh peralatan (Zaluchu, 2015). "Perempuan cenderung berperan sebagai pembantu laki-laki atau "ngoni-ngoni". Norma sosial juga mengharuskan perempuan untuk hormat kepada laki-laki, sang 'högö' atau 'kepala'” (Mita, Lase, Anggraini, 2016, 2). 
Mata pencaharian penduduk yang utama adalah pertanian, yakni tanaman pangan. Selain itu ada perkebunan rakyat yaitu karet, kelapa, kakao dan beberapa komoditi yang lain seperti kopi, cengkeh, pala dan dan nilam. Peternakan juga termasuk mata pencaharian, yaitu babi, kambing, sapi dan kerbau. Untuk masyarakat yang tinggal di daerah pesisir pantai, perikanan menjadi mata pencaharian mereka (Sari dan Nurul, 2011).

Data menunjukkan bahwa jumlah penduduk perempuan di semua kecamatan lebih besar dari pada laki-laki. Di samping itu, budaya masyarakat Nias masih erat pada sistem budaya patriarki sehingga perempuan kurang mendapat peran yang signifikan dalam masyarakat. Oleh karena itu, untuk memberdayakan perempuan di Kabupaten Nias, diperlukan model pemberdayaan ekonomi dengan memperhatikan keterlibatan perempuan. Tujuannya agar perempuan dapat berpartisipasi aktif memanfaatkan sumber daya lokal, karena keberdayaan perempuan di bidang ekonomi adalah salah satu indikator meningkatnya kesejahteraan.

\section{PEMBAHASAN}

Kabupaten Nias yang termasuk wilayah daerah tertinggal terdiri dari 10 kecamatan yaitu: Bawölato, Botomuzöi, Gidö, Hili Serangkai, Hiliduho, Idanögawo, Ma'u, Somölömölö, Ulugawo, dan Sogae'adu.. Dari 10 kecamatan, Kecamatan Gidö, merupakan wilayah yang sebagian daerahnya dekat dengan perkotaan dan ibu kota Kabupaten Nias terletak di kecamatan tersebut. Pendapatan rumah tangga di Kecamatan Gidö bersumber dari usaha pertanian, ternak dan perkebunan. Perempuan juga terlibat dalam memenuhi kebutuhan rumah tangga mereka, tanpa meninggalkan tugas utama sebagai ibu. Sehingga cenderung mendapatkan beban ganda. Perempuan ikut bekerja di ladang dan memelihara ternak, terutama ternak babi. Setiap hari mereka mencari daun 
ubi untuk pakan babi disamping mengurus rumah, anak dan suami. Terdapat juga perempuan yang bekerja di kebun karet, baik milik sendiri maupun orang lain. Karena kondisi cuaca yang tidak stabil, harga karet dapat merosot tajam, sehingga kesulitan ekonomi. Kondisi tersebut sangat memprihatinkan. Mereka tidak punya banyak pilihan untuk meningkatkan kehidupan ekonominya. Pengembangan kegiatan ekonomi produktif di wilayah tersebut mengalami kendala modal sebagai variabel penting untuk menggerakkan perekonomian desa. Keterbatasan infrastruktur membuat perempuan sulit dalam memperoleh sumber pendapatan. Fasilitas pelayanan umum, seperti pendidikan, kesehatan transportasi umum dan komunikasi juga relatif terbatas.

Pemberdayaan perempuan di wilayah daerah tertinggal seperti di Kecamatan Gidö, Kabupaten Nias perlu dilakukan. Memberdayakan adalah upaya untuk memampukan dan memandirikan masyarakat dengan mencipatkan suasana yang memungkinkan potensi masyarakat berkembang (Hastuti dan Respati, 2009). Pemberdayaan di sini sebagai upaya meningkatkan kualitas perempuan pedesaan agar mampu memanfaatkan sumber daya lokal. Kalau selama ini perempuan Nias ditempatkan di sektor domestik, sehingga cenderung tidak produktif, maka dengan diberdayakannya kaum perempuan akan ikut berperan dalam menentukan pendapatan keluarga. Model pemberdayaan ekonomi perempuan berbasis sumber daya lokal sebagai upaya untuk meningkatkan kehidupan ekonomi keluarga.

Pendekatan partisipasi merupakan hal yang utama dalam model pemberdayaan ini. Pendekatan ini diharapkan mampu mengajak perempuan Nias terlibat untuk meningkatkan kualitas diri. Kerja secara kelompok sangat diperlukan, karena dengan cara demikian antara anggota kelompok dan ketua serta fasilitator dapat saling berbagi. Pendekatan ini diyakini sebagai sebagai cara yang fleksibel, karena lebih disesuaikan 
dengan situasi di lapangan dengan memperhatikan kondisi, potensi dan minat kaum perempuan maupun ketersediaan sumber daya.

Di bawah ini adalah Model Pemberdayaan ekonomi yang dapat diterapkan di Kecamatan Gido, Kabupaten Nias.

Tabel 2. Model Pemberdayaan Ekonomi Perempuan di Kabupaten Nias Berbasis Sumber Daya Lokal

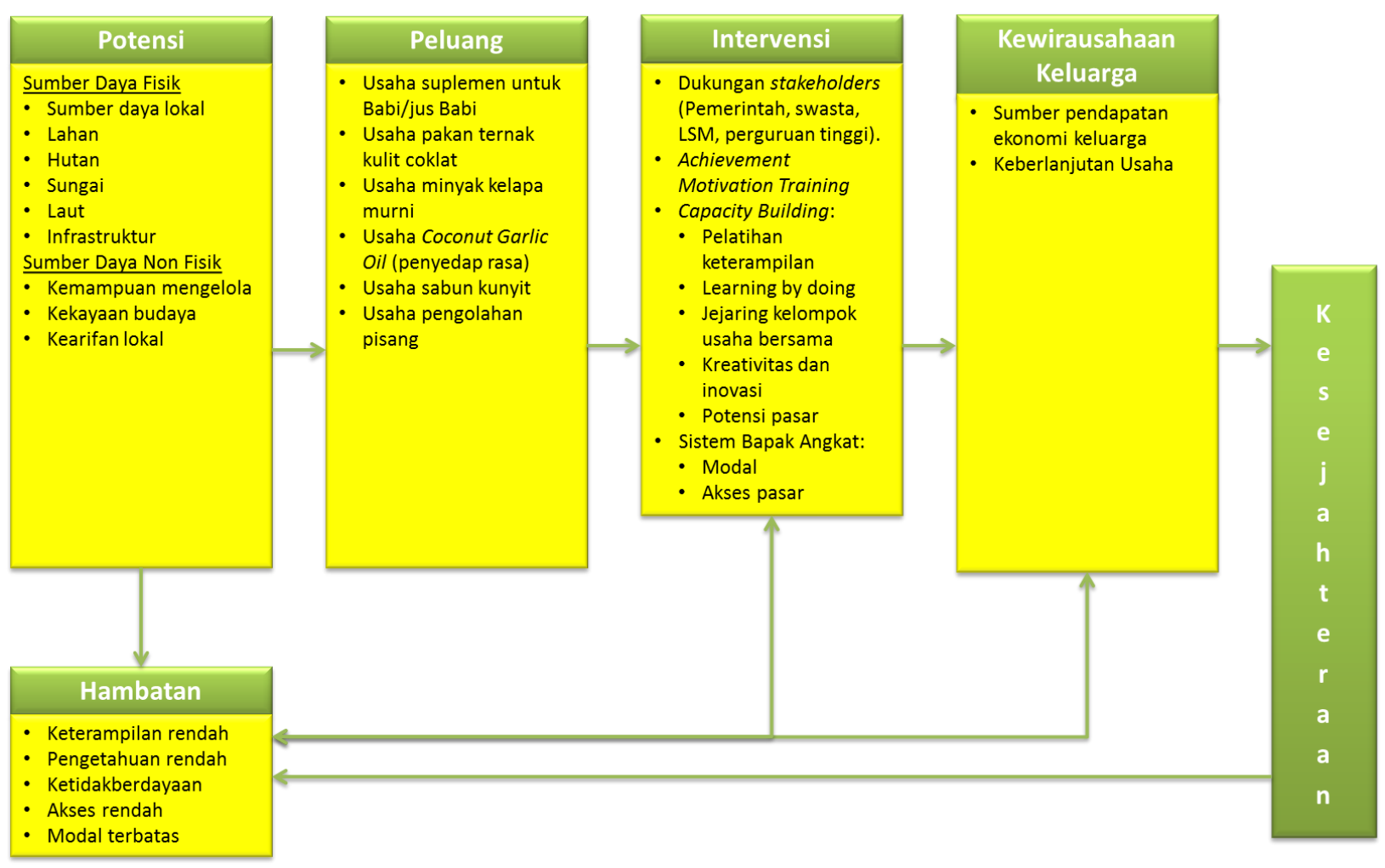

Wilayah Kabupaten Nias, khususnya Kecamatan Gidö pada satu sisi memiliki potensi sumber daya fisik, seperti sumber daya lokal, lahan, hutan, sungai, laut dan infrastruktur; dan juga sumber daya nonfisik, seperti kemampuan mengelola sumber daya, kekayaan budaya dan berbagai kearifan lokal. Tetapi, ada hambatan, yaitu rendahnya kualitas sumber daya manusia. Hal ini mengakibatkan masyarakat tidak berdaya dan sulit mengakses modal. 
Namun masyarakat Kecamatan Gidö, Kabupaten Nias, tetap mempunyai peluang. Ada banyak usaha yang dapat dikembangkan dengan memanfaatkan sumber daya lokal. Peluang usaha yang memungkinkan adalah produksi suplemen untuk babi (jus babi), usaha pakan ternak kulit coklat, usaha minyak kelapa murni, usaha coconut garlic oil (untuk penyedap masakan), usaha sabun kunyit dan usaha pengolahan pisang. Semua bahan-bahan untuk usaha di atas tersedia dalam jumlah cukup banyak, bahkan ada yang dibuang, seperti kulit coklat. Di samping itu hampir semua rumah tangga di Kecamatan Gidö, Kabupaten Nias memelihara babi dengan jumlah yang tidak terlalu banyak. Jus babi yang merupakan suplemen untuk babi akan bermanfaat untuk mempercepat penggemukan babi. Demikian pula buah kelapa banyak sekali dijumpai di wilayah Nias yang selama ini hanya dijual apa adanya. Jika sumber daya lokal ini bisa diolah maka dapat memiliki nilai tambah. Secara ringkas dapat dikatakan bahwa Nias memerlukan teknologi untuk mengolah sumber daya lokal yang ada sehingga dapat dimanfaatkan untuk meningkatkan kesejahteraan mereka.

Dalam rangka memberdayakan perempuan Nias, sangat diperlukan intervensi dari beberapa pihak, antara lain, perlunya dukungan stakeholders (pemerintah, swasta, LSM, perguruan tinggi). Tanpa dukungan dari beberapa pihak di atas, maka program pemberdayaan perempuan tersebut akan sulit terwujud.

Sebagai langkah awal, para perempuan perlu dimotivasi terlebih dahulu dengan diberi pelatihan Achievement Motivation Training secara singkat. Selanjutnya perlu juga ditingkatkan kapasitasnya dengan diberi pelatihan keterampilan, belajar sambil praktik usaha, membuat jejaring kelompok usaha bersama, didorong untuk kreatif dan inovatif serta ditunjukkan potensi pasar wilayah tersebut. Selain itu juga diberi kemudahan untuk mendapatkan modal dan akses pasar 
Dari hal tersebut, maka akan terbentuklah usaha-usaha kecil dengan perempuan sebagai pelakunya. Diharapkan usaha tersebut akan menjadi sumber pendapatan ekonomi keluarga dan ke depan akan ada keberlanjutan usaha yang pada akhirnya akan dapat meningkatkan kesejahteraan bagi masyarakat secara umum. Melalui intervesi yang sudah dilakukan dan terbentuknya usaha-usaha keluarga, maka hambatanhambatan yang dihadapi dapat diatasi dan usaha dapat berkembang dan kesejahteraan akan tercapai.

Tantangan yang dihadapi dalam mengimplementasikan model pemberdayaan ini adalah menumbuhkan kesadaran pada perempuan berpartisipasi secara aktif dalam setiap kegiatan peningkatan pengetahuan, keterampilan dan menjalankan usaha bersama. Oleh karena itu diperlukan kerja sama yang sinergis antara para pendukung, baik pemerintah maupun swasta dan tentu saja dari kaum perempuan Nias sendiri.

\section{PENUTUP}

Pemberdayaan ekonomi perempuan Nias dilakukan dengan meningkatkan kemampuan dan melibatkan perempuan untuk dapat berpartisipasi secara aktif dalam memanfaatkan sumber daya lokal. Perempuan di ajak berpartisipasi dalam mengembangkan kegiatan produktif melalui peningkatan keterampilan dan pengetahuan secara optimal dan berkelanjutan. Pengembangan model pemberdayaan yang ditawarkan diharapkan dapat dimplentasikan dengan memperhatikan potensi dan hambatan yang ada serta senantiasa mendorong kaum perempuan untuk mau terlibat secara aktif dan berkelanjutan dalam rangka meningkatkan kehidupan ekonomi keluarga. 


\section{REFERENSI}

Anggraini, Nenny, Mita Yesyca, dan Formas Juitan Lase. 2016. Pemetaan Kekerasan Antarpribadi Terhadap Perempuan di Daerah Tertinggal: Studi di Kabupaten Nias 2009-2016. Jakarta: Pusat Studi Wanita Universitas Kristen Indonesia.

Biro Pusat Statistik. 2015. Data Statistik Kabupaten Nias. Kota Gunungsiotli: Biro Pusat Statistik Kabupaten Nias.

Hastuti, Dyah Respati. 2009. Model Pemberdayaan Perempuan Miskin Berbasis Pemanfaatan Sumberdaya Pedesaan Upaya Pengentasan Kemiskinan Pedesaan. Yogayakarta: Universitas Negeri Yogyakarta.

Kumala Sari, Nurul. 2011. "Peranan Perempuan Nias Desa "Boronadu”', diakses dari http://nurulantropologi.blogspot.co.id/2011/11/gender.html

Yesyca, Mita, Formas Juitan Lase dan Nenny Anggrani. 2018. Mapping Interpersonal Violence Againts Women in the District of Nias, 2009-2016, Jurnal Masyarakat, Kebudayaan, dan Politik Vol 31, No 1 (2018), http://dx.doi.org/10.20473/mkp.V31I12018.24-35

Zaluchu, Fotarisman. 2015. “Tragedi Perempuan Nias, Sampai Kapan?”, Nias Bangkit, 8 Mei, diakses dari http://nias-bangkit.com/2015/05/tragedi-perempuan-niassampai-kapan/ 